\title{
Influence of Cutting Parameters to Surface Area Roughness in Dimple Machining Using Milling Process
}

\author{
M.A. Hanafiah ${ }^{1}$, A.A Aziz² and A.R Yusoff ${ }^{3}$ \\ ${ }^{1}$ Faculty of Engineering Technology Manufacturing \& Mechatronics, Universiti Malaysia Pahang, 26600 Pahang, Malaysia. \\ 2Faculty of Engineering Technology Mechanical \& Automotive, Universiti Malaysia Pahang, 26600 Pahang, Malaysia \\ ${ }^{3}$ College of Engineering, Universiti Malaysia Pahang, 26600 Pahang, Malaysia
}

\begin{abstract}
Surface quality is among the predominant criterion in measuring machining process performance, including milling. It is extremely dependent on the process variable, such as cutting parameters and cutting tool conditions. The main intention of this research work is to study the effect of the milling machining parameters, including depth of cut, spindle speed, feed rate as well as machining pattern to the final surface area roughness of the fabricated dimple structure. The concave profile of the dimple is machined at the right angle to a flat Al6061 specimen using a ball end mill attached to a 3-axis CNC milling machine, and the surface area of the concave profile is measured using 3D measuring laser microscope. It is observed that surface area roughness reacts with the spindle speed and feed rate with different tool sizes. Based on the result gained, the work has successfully characterised the influence of studied milling parameters on the dimple surface area roughness, where within the range of the studied parameter, the surface area roughness varies only less than $2.2 \mu \mathrm{m}$. The research work will be continued further on the incline milling technique and micro size ball end mill.
\end{abstract}

ARTICLE HISTORY

Received: $27^{\text {th }}$ Jan 2021

Revised: 30 ${ }^{\text {th }}$ April 2021

Accepted: 20th Sept 2021

\section{KEYWORDS}

Functional surfaces;

Micro-dimple;

Milling process;

Ball nose end mill;

Surface area roughness

\section{INTRODUCTION}

Recently, the demand for micro features based machining has increased drastically due to technological advancement in various fields such as biomedical, orthopaedic implants, tribological applications, aerospace industry, automotive industry, sensory devices, electronics cooling devices, optics, and microfluidics [1][2][3]. In tribological applications, micro features-based such as dimple, groove, and scale often applied to improve the performance of the part, especially in minimising wear and friction on sliding mechanical components [4][5]. The micro features-based are fabricated on the designated sliding surface to act as a lubricant reservoir as well as reducing contact area in-between during the surface in motions.

In general, various machining processes could be employed to manufacture the dimple either by conventional or nonconventional such as milling, turning, electro discharge machining (EDM), chemical etching, electrochemical machining (ECM), abrasive jet machining and laser beam machining [6]. Despite numbered fabrication processes, milling machining still considered a viable and flexible process at a lower cost. It is due to the capability to produce the micro dimple with a wide variety of materials, different types of dimple patterns, as well as micro profile itself such as dimple, groove and pyramid [7].

As far as milling machining is considered, surface roughness is one of the key features influencing the quality of the machined surface or parts. Based on the number of past studies done [7][8][9], revealed that the roughness of machined surfaces depends greatly on the machining parameters and condition of the cutting tools. The machining parameters basically referred to three relative motions of the cutting tool, including the rotational speed of the cutting tool, advancement of cutting tool towards work material along the intended path or also known as feed rate and the penetration motion below the workpiece surface to necessary depth so-called depth of cut. In fact, the simultaneous action of all these three relative motions has resulted in the advancement of the cutting tool along the intended toolpath generating the intended shape. A study on the influence of process parameters on the surface roughness also has addressed the surface roughness inversely proportional to the spindle speed and directly proportional to tool feed rate and depth of cut [9]. In other words, good surface quality can be achieved by a combination of high spindle speed, low feed rate, and low depth of cut.

Meanwhile, the condition of the cutting tool refers to the current state of wear at the tool cutting edge. Soon as the cutting process started, the smooth and sharp tool cutting edge is progressively worn off, causing an increase of roughness at the cutting edge. In turn, the rough tool cutting edge will be imprinted to the machined surface and deteriorate its roughness. Based on the study done on the effect of tool wear on final surface roughness at micro-level, tool wear directly proportional to the numbers of machined micro-dimple or materials removed volume [10][11][12]. Despite the effect on the surface quality of the machined workpiece, tool wear also causing a significant increase in measured cutting force during machining [13], as well as excessive force, lead to tool breakage, which possibly led to decreased productivity. 
According to past research done on the application of milling to fabricate a micro-dimple, most of the research approached are done intensively on hemispherical shape dimple using ball end mill tool. It is due to the hydrodynamic performance of the round shape dimple [14] and the capability of the ball end mill cutting tool to form the concave profile of the micro-dimple with acceptable quality. Meanwhile, the current research trend of dimple fabrication using milling machining is using the high-speed method where the spindle speed used could reach up to $80,000 \mathrm{rpm}$. Unlike others, this paper aims to study in depth the round dimple (hemispherical shape) fabrication using low spindle speed range (less than $10,000 \mathrm{rpm}$ ), as well as investigate the interaction of milling process parameters such as spindle speed and feed rate to the surface area roughness of the dimple structure.

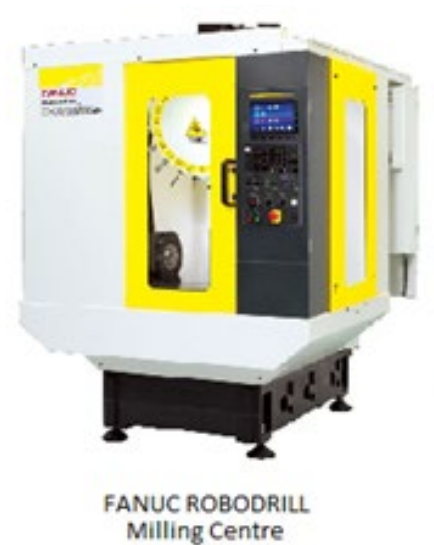

(a)

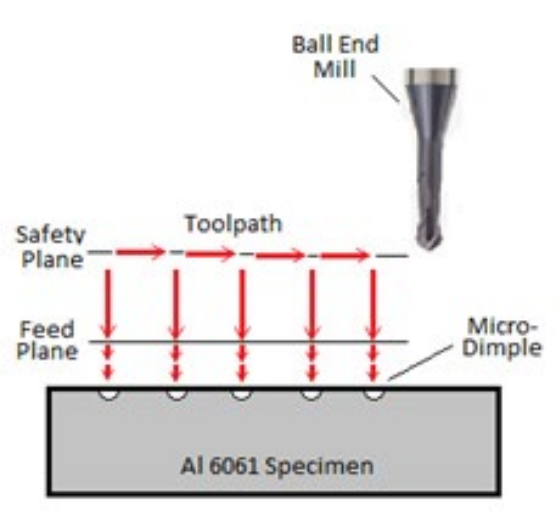

(b)

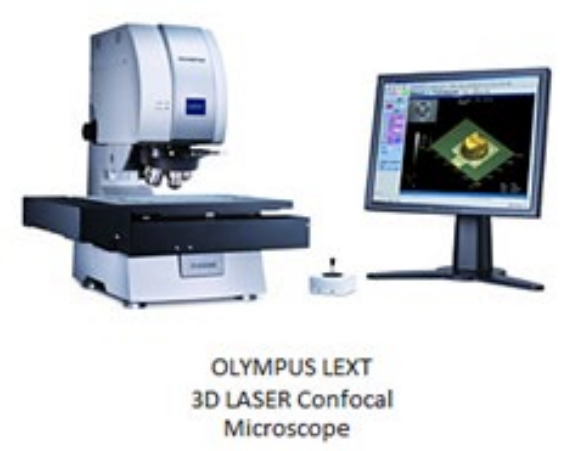

(c)

Figure 1. (a) FANUC Robodrill used in the experiment, (b) cutting toolpath to machine micro-dimple, and (c) 3D LASER confocal microscope for the surface topography measuring.

\section{METHODOLOGY}

The research work begins with a parametric study to analyse the significant machining parameters affecting the response factor; the surface area roughness in dimple milling machining. Followed by experiment work to machine the dimple with various parameters set to imprint the effect to the dimple profile. Then the machined dimple profile is measured accordingly for data collection and data analysis purposes.

\section{Experimental Setup and Procedure}

In the experimental work, two significant machining parameters were manipulated [9] and varied to fabricate a dimple profile (round convex profile) using different sizes of ball end mill. These two machining parameters include spindle speed, and feed rate that varies within the range of 4000-8000 rpm and 6-10 $\mathrm{mm} / \mathrm{min}$, respectively, while the depth of cut was constant at $0.4 \mathrm{~mm}$ to maintain the dimple aspect ratio of 0.4 for the smallest tool size. The experiment was conducted using FANUC Robodrill 3-axis CNC Milling Centre with a pre-programmed toolpath according to the designated dimple position, as shown in Figure1(a). The coated high-speed steel (HSS) ball end mill tool size ranging from 1.0 to $4.0 \mathrm{~mm}$ diameter were used to machine the dimple profile. In order to ease the data analysis, the spindle speed and feed rate were grouped into three groups named parameter set 1 to set 3 . The parameter values of spindle speed and feed rate in parameter set 1 to set 3 were arranged in increasing order, as shown in Table 1.

Table 1. Grouped milling machining parameters for data analysis.

\begin{tabular}{lcc}
\hline Parameter & Spindle speed $(\mathrm{rpm})$ & Feed rate $(\mathrm{mm} / \mathrm{min})$ \\
\hline Set 1 & 4000 & 6 \\
Set 2 & 6000 & 8 \\
Set 3 & 8000 & 10 \\
\hline
\end{tabular}

The dimple profile will be machined using two different tool paths of zig-zag and linear to form different dimple patterns, as shown in Figure 2. The toolpath programming in Figure 1(b) begins with positioning motion to the intended position at safety plane followed by descending motion to feed plane and then plunging motion of the ball end mill tool to perform the cutting operation shown in Figure 1(b). At this point (plunging motion), the tool forms the dimple with different feed rates (in the z-axis) and depth of cut fixed at $0.4 \mathrm{~mm}$ before the ball end mill tool re-track to z-axis safety plane. The cycle was repeated for the next position until the 10th micro-dimple to form the pattern, as well as to ensure the consistency, repeatability and reliability of the results.

\section{Surface Area Measuring}

In the experimental work, the machined specimen with the micro-dimple profile was measured to evaluate its surface roughness resulting from the machining operation, sizes and the complexity of the dimple profile. It required special measuring equipment capable of measuring the roughness on the tiny curvature surface of the dimple. Due to that, this 
study has employed the Olympus LEXT 3D LASER Confocal Microscope specifically for measuring purposes, as in Figure 1(c). Based on the analysis requirement, two types of measurement have been carried out to the micro-dimple specimen, geometrical and surface roughness. The geometrical measurement determines the diameters and depths of the dimple. Meanwhile, the roughness of the inside curvature surface is measured and denoted as surface area roughness, $S_{a}$. The image capturing for both geo-metrical and surface roughness measurement of the dimple profile uses $10 \times$ magnification lenses. In geometrical image analysing, the dimple depth and radius used height and profile analysis, respectively, as shown in Figure 3.

\section{RESULTS AND DISCUSSION}

The resulted dimples are shown in Figure 2, while the measured surface area roughness, $S_{a}$, is tabulated in Table 2, where the value is based on the calculated average measured value. Meanwhile, the geometrical measurement (for diameters) of the micro-dimple specimen has been tabulated in Table 3 and arranged graphically into Figure 3 (based on the generated report from the Olympus LEXT 3D LASER confocal microscope). The image captured in geometrical measurement was done by applying a high pass filter to the roughness profile to remove the surface waviness with a wavelength cut-off, $\lambda_{c}$ of $0.08 \mathrm{~mm}$, based on the recommendation from ISO 4288-1996 [15].

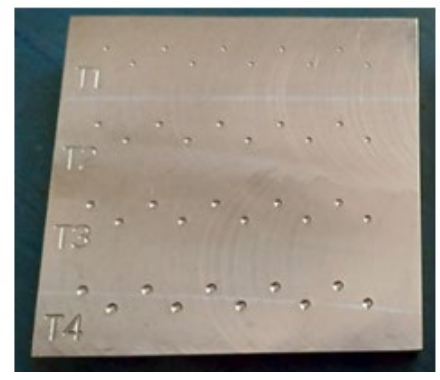

(a)

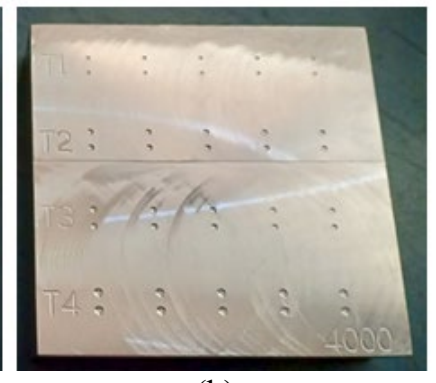

(b)

Figure 2. Dimple machined on Al6061 block with (a) zig-zag pattern and, (b) parallel pattern.

Table 2. Result of measured dimple diameter and calculated standard deviation for each tool size.

\begin{tabular}{|c|c|c|c|c|c|c|c|c|c|c|c|c|}
\hline \multirow{2}{*}{$\begin{array}{l}\text { Tool size } \\
(\mathrm{mm})\end{array}$} & \multicolumn{10}{|c|}{ Diameter measurement } & \multirow{2}{*}{ Mean } & \multirow{2}{*}{$\begin{array}{l}\text { Std. } \\
\text { dev. }\end{array}$} \\
\hline & D1 & D2 & D3 & D4 & D5 & D6 & D7 & D8 & D9 & D10 & & \\
\hline$\varnothing 1.0$ & 1.464 & 1.458 & 1.478 & 1.532 & 1.542 & 1.437 & 1.440 & 1.511 & 1.423 & 1.495 & 1.48 & 0.041 \\
\hline$\varnothing 2.0$ & 1.891 & 1.924 & 1.842 & 1.872 & 1.896 & 1.891 & 1.88 & 1.883 & 1.892 & 1.879 & 1.89 & 0.021 \\
\hline$\varnothing 3.0$ & 2.194 & 2.199 & 2.207 & 2.191 & 2.220 & 2.187 & 2.198 & 2.201 & 2.182 & 2.181 & 2.20 & 0.012 \\
\hline$\varnothing 4.0$ & 2.396 & 2.382 & 2.388 & 2.376 & 2.397 & 2.391 & 2.384 & 2.386 & 2.380 & 2.360 & 2.38 & 0.011 \\
\hline
\end{tabular}

Figure 3(a), 3(b) and Table 4 show the result of the measured dimple height for all ball end mill sizes. It is observed that the average measured dimple depth machined by specific tool diameters is less than the depth of cut (DOC) setup during toolpath programming, which is $0.4 \mathrm{~mm}$. This could be due to the accuracy of tool presetting for the z-axis height and the workpiece flatness during the fabrication process. Whereas for diameters measurements, it is found that the average measured diameter of the dimples is slightly less than the tool diameter for all tool sizes except for tool diameter $\varnothing 1.0 \mathrm{~mm}$. For dimples machined by tool diameter of $\varnothing 1.0 \mathrm{~mm}$, the diameter of the dimple is slightly larger than the tool diameter, although the depth of cut is just $0.4 \mathrm{~mm}$. Although the average measured dimple diameter values are inconsistent, but does not affect the surface area roughness and consistent within the same parameter groups. This could possibly due to excessive tool runout and may cause by a defect cutting tool or wear off collet arbour since these results only occur to the tool diameters of $1.0 \mathrm{~mm}$.

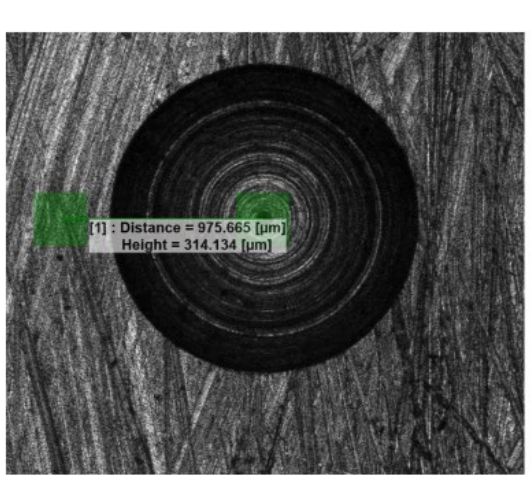

(a)

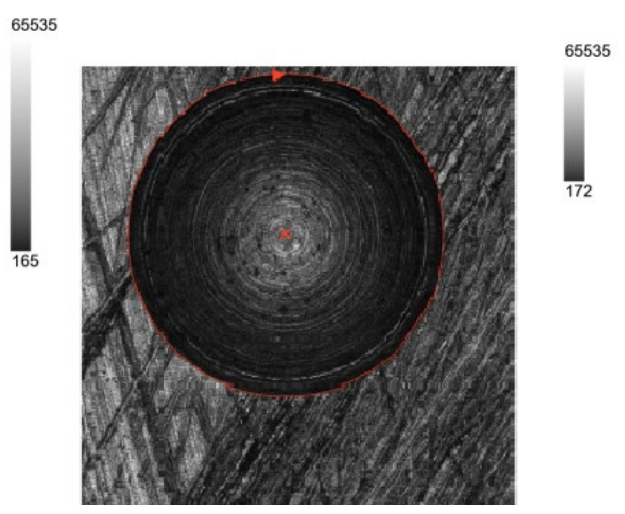

(b) 


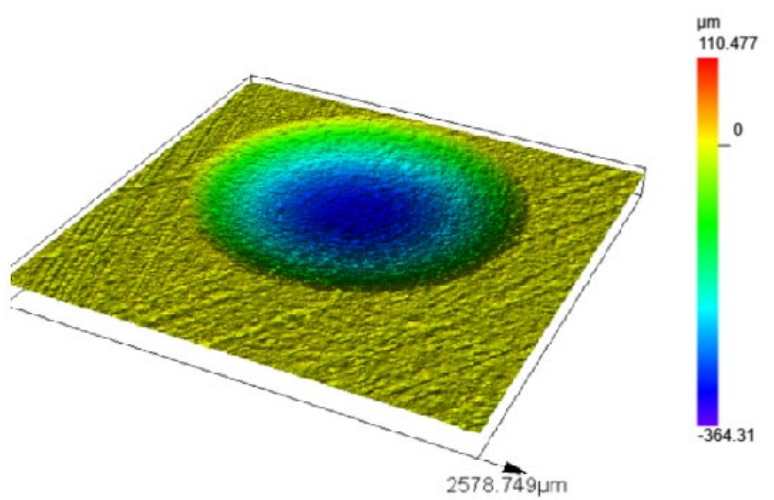

(c)

Figure 3. 2D image of measured (a) dimple depth (b) and diameter, and (c) 3D image of measured dimple with a colour scale.

Table 3. Result of the measured dimple surface area roughness using 3D LASER confocal microscope.

\begin{tabular}{|c|c|c|c|c|c|}
\hline Input factors & & & & & Response factor \\
\hline $\begin{array}{l}\text { Tool diameter } \\
(\mathrm{mm})\end{array}$ & $\begin{array}{l}\text { Depth of } \\
\text { cut }(\mathrm{mm})\end{array}$ & $\begin{array}{l}\text { Plunging feed rate } \\
(\mathrm{mm} / \mathrm{min})\end{array}$ & $\begin{array}{c}\text { Spindle speed } \\
\text { (rev/minute) }\end{array}$ & Pattern & $\begin{array}{c}\text { Surface area roughness, } S_{a} \\
(\mu \mathrm{m})\end{array}$ \\
\hline \multirow{6}{*}{1.0} & \multirow{6}{*}{0.4} & \multirow{2}{*}{6} & \multirow{2}{*}{4000} & Linear & 6.604 \\
\hline & & & & Zig-zag & 6.108 \\
\hline & & \multirow{2}{*}{8} & \multirow{2}{*}{6000} & Linear & 6.186 \\
\hline & & & & Zig-zag & 6.291 \\
\hline & & \multirow{2}{*}{10} & \multirow{2}{*}{8000} & Linear & 6.263 \\
\hline & & & & Zig-zag & 5.777 \\
\hline \multirow{6}{*}{2.0} & \multirow{6}{*}{0.4} & \multirow{2}{*}{6} & \multirow{2}{*}{4000} & Linear & 6.759 \\
\hline & & & & Zig-zag & 6.820 \\
\hline & & \multirow{2}{*}{8} & \multirow{2}{*}{6000} & Linear & 6.709 \\
\hline & & & & Zig-zag & 6.826 \\
\hline & & \multirow{2}{*}{10} & \multirow{2}{*}{8000} & Linear & 6.491 \\
\hline & & & & Zig-zag & 6.308 \\
\hline \multirow{6}{*}{3.0} & \multirow{6}{*}{0.4} & \multirow{2}{*}{6} & \multirow{2}{*}{4000} & Linear & 6.122 \\
\hline & & & & Zig-zag & 6.063 \\
\hline & & \multirow{2}{*}{8} & \multirow{2}{*}{6000} & Linear & 6.055 \\
\hline & & & & Zig-zag & 6.143 \\
\hline & & \multirow{2}{*}{10} & \multirow{2}{*}{8000} & Linear & 7.872 \\
\hline & & & & Zig-zag & 7.269 \\
\hline \multirow{6}{*}{4.0} & \multirow{6}{*}{0.4} & \multirow{2}{*}{6} & \multirow{2}{*}{4000} & Linear & 5.742 \\
\hline & & & & Zig-zag & 6.154 \\
\hline & & \multirow{2}{*}{8} & \multirow{2}{*}{6000} & Linear & 5.636 \\
\hline & & & & Zig-zag & 5.959 \\
\hline & & \multirow{2}{*}{10} & \multirow{2}{*}{8000} & Linear & 6.336 \\
\hline & & & & Zig-zag & 6.383 \\
\hline
\end{tabular}

Table 4. Results of average measured dimple depth.

\begin{tabular}{lc}
\hline Tool size, $\varnothing(\mathrm{mm})$ & Dimple depth $(\mathrm{mm})$ \\
\hline 1.0 & 0.314 \\
2.0 & 0.308 \\
3.0 & 0.322 \\
4.0 & 0.352 \\
\hline
\end{tabular}

From dimple roughness analysis, graph (a) and (b) in Figure 4 shows the surface area roughness, $S_{a}$ versus the parameter set for ball end mill diameter of $\varnothing 1.0 \mathrm{~mm}$ and $\varnothing 2.0 \mathrm{~mm}$. Using the $\varnothing 1.0 \mathrm{~mm}$ cutting tool, the surface area roughness, $S_{a}$ varies from 6.186 ( $\mathrm{min}$.) to 6.604 (max.) within a range of $0.418 \mu \mathrm{m}$ and varies from 5.777 (min.) to 6.291 (max.) within a range of $0.514 \mu \mathrm{m}$ for linear and zig-zag patterns, respectively. For the $\varnothing 2.0 \mathrm{~mm}$ cutting tool, the surface area roughness, $S_{a}$ varies from 6.491 ( $\mathrm{min}$.) to 6.759 (max.) within a range of $0.268 \mu \mathrm{m}$ and varies from 6.308 (min.) to 6.826 (max.) within a range of $0.518 \mu \mathrm{m}$ for linear and zig-zag patterns, respectively.

Meanwhile, graph (c) and (d) of Figure 4 shows the surface area roughness, $S_{a}$ versus parameter set for ball end mill diameter $\varnothing 3.0 \mathrm{~mm}$ and $\varnothing 4.0 \mathrm{~mm}$. Using the $\varnothing 3.0 \mathrm{~mm}$ cutting tool, the surface area roughness, $S_{a}$ varies from 6.055 (min.) to 7.872 (max.) within a range of $1.817 \mu \mathrm{m}$ and varies from 6.063 (min.) to 7.269 (max.) within a range of $1.206 \mu \mathrm{m}$ for 
linear and zig-zag patterns, respectively. The $\varnothing 4.0 \mathrm{~mm}$ cutting tool surface area roughness $S_{a}$ varies from 5.636 (min.) to 6.3336 (max.) within a range of $0.7 \mu \mathrm{m}$ and varies from 5.959 (min.) to 6.383 (max.) within a range of $0.424 \mu \mathrm{m}$ for linear and zig-zag pattern respectively.

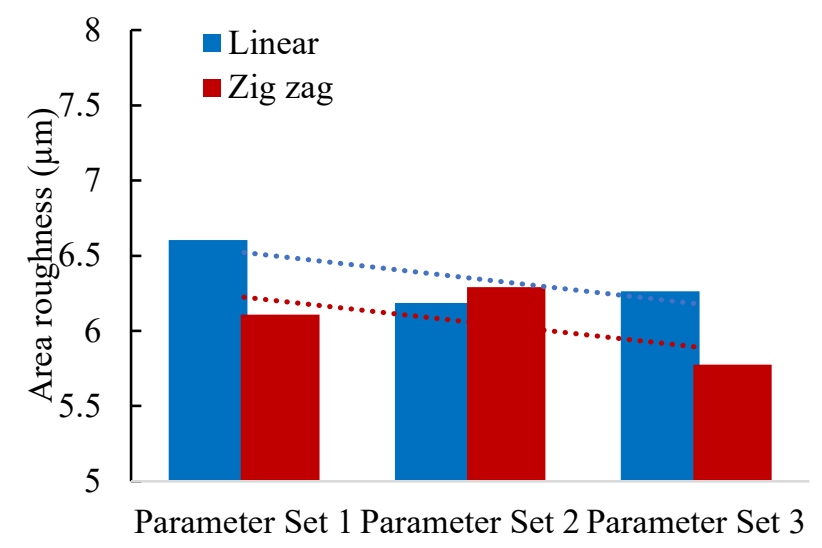

(a) $\varnothing 1.0 \mathrm{~mm}$ ball end mill

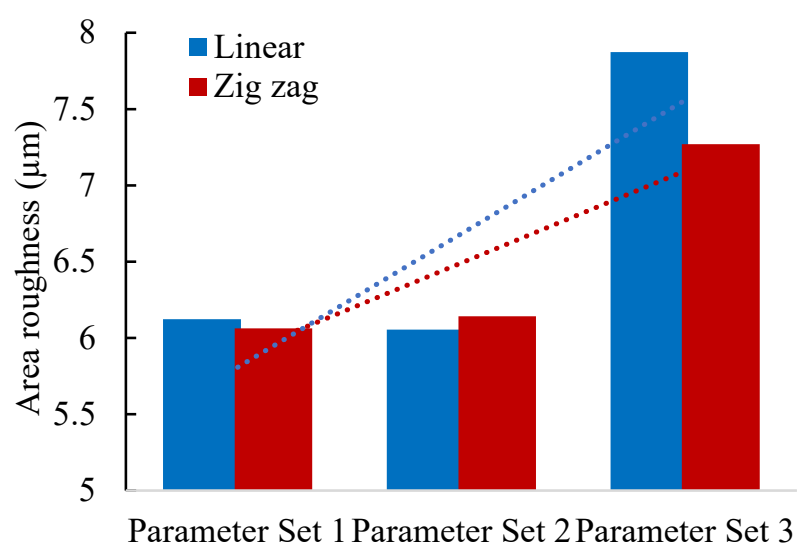

(c) $Ø 3.0 \mathrm{~mm}$ ball end mill

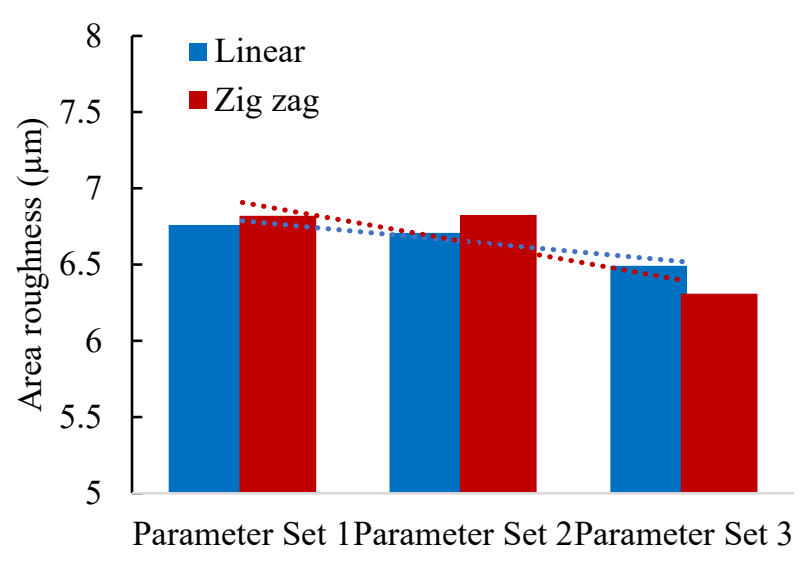

(b) $\varnothing 2.0 \mathrm{~mm}$ ball end mill

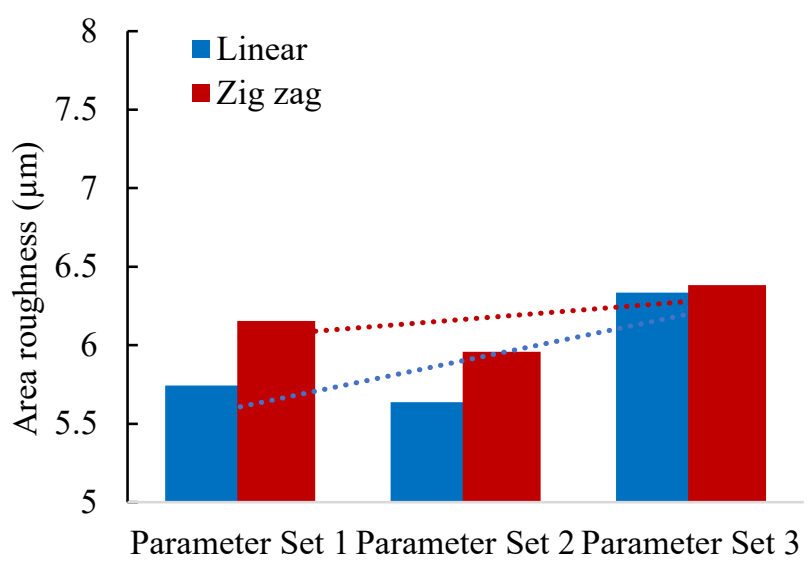

(d) $\varnothing 4.0 \mathrm{~mm}$ ball end mill

Figure 4. Graphical analysis on the effect of spindle speed/RPM and feed rate for different tool diameters.

Based on the results, the surface area roughness, $S_{a}$ reacts with the increase of spindle speed, $n$ and feed rate, $f_{r}$ regardless of the tool size and pattern. The surface area roughness, $S_{a}$ reaction trend differs with different tool size. For the tool with $\varnothing 1.0$ and $\varnothing 2.0 \mathrm{~mm}$, surface area roughness slightly decreased with the increase of spindle speed and feed rate, as shown in Figure 5. In contrast with tool size $\varnothing 3.0$ and $\varnothing 4.0 \mathrm{~mm}$ where surface area roughness, $S_{a}$ shows a slight increment with increasing spindle speed and feed rate (in Figure 5). Meanwhile, the analysis results also show that the surface area roughness reaction trend is almost identical to each other for the linear and zig-zag patterns of the same tool size. In general, for all machining parameters set, the surface area roughness, Sa) results vary within a range of 5.5 to 8.0 $\mu \mathrm{m}$. As for benchmarking purposes, the dimple surface roughness machined using high-speed milling method could reach less than $1 \mu \mathrm{m}[10][16]$. As expected, the surface area roughness $\left(S_{a}\right)$ is higher than the dimple machined using highspeed milling method, which having spindle speed up to $80000 \mathrm{rpm}$ 


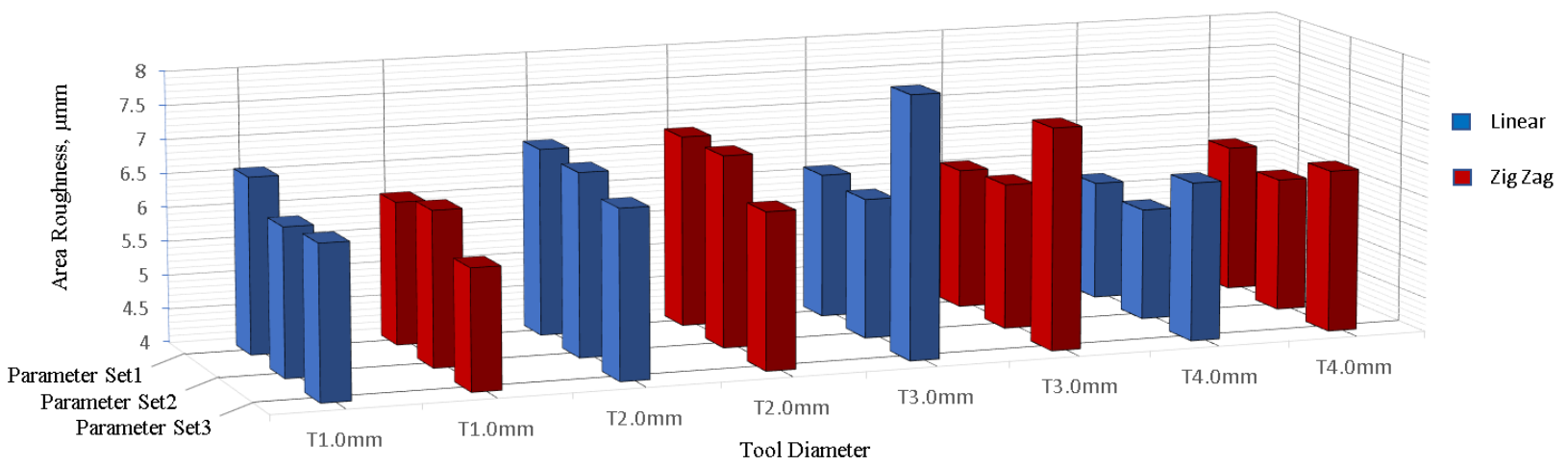

Figure 5. Surface area roughness versus parameter set (spindle speed/feed rates) for all tool sizes.

Apart from machining parameters, another perspective that could possibly lead to high surface area roughness, $S_{a}$ in ball-end milling, is the 'rubbing effect' of the ball end mill tool as reported previously [17]. The hemispherical shape of the ball end mill caused a variable cutting speed from zero at the centre of the tooltip to the maximum of the tool radius, as in Figure 6(a). This phenomenon causing the ball tip or region near the tool rotation axis to have almost zero cutting velocity and constantly rubbing with the workpiece surface in case of tool and workpiece is in a perpendicular position to each other. This rubbing effect increases the cutting force magnitude as well as produces a poor surface finish, as shown in Figure 6(b), along with shorter tool life. According to others research work [18,19], the rubbing effect could be counter by slanting the workpiece or by inclining the tool. This technique avoiding the low cutting speed region to have contact during machining and ensure the contact point of tool and workpiece displaced away from the tool centre axis Figure 6(c), thus minimising the effect as well as helps to improve the surface finish.

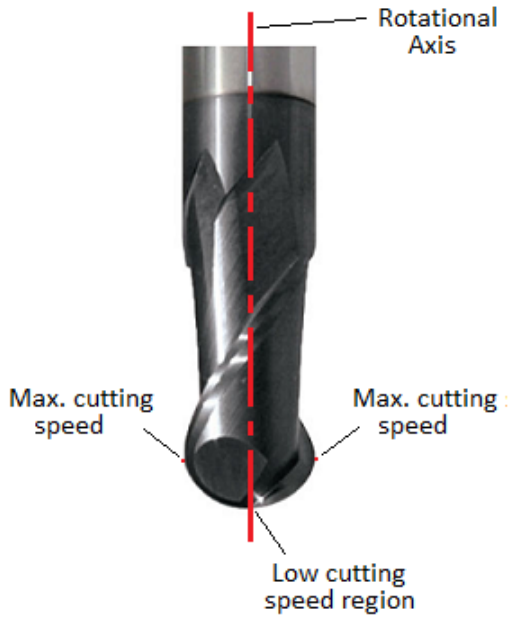

(a)

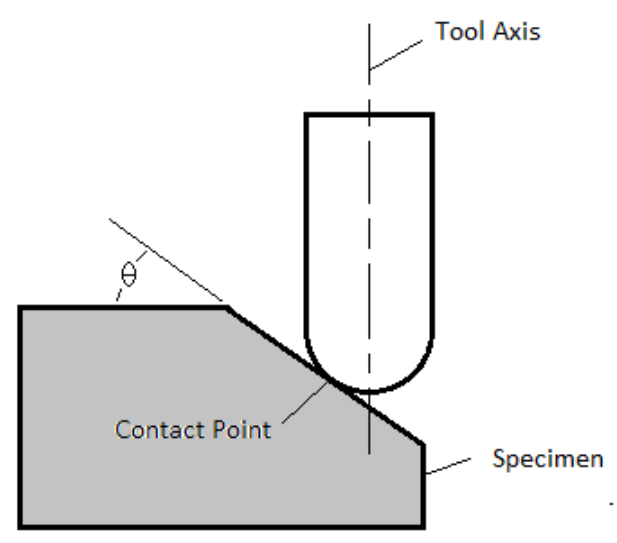

(b)

Figure 6. (a) Cutting speed variation on ball end mill tool, and (b) position of contact point tool and workpiece.

\section{CONCLUSION}

In this experiment, the main concern is to analyse the correlation between spindle speed, feed rate, tool size and pattern to the dimple surface area roughness. Based on the result gained and data analysis, it proves that the work has successfully characterised the influence of studied milling parameters on the dimple surface area roughness. Other than that, the study concludes:

i. The surface area roughness, $S_{a}$ reacts with increasing spindle speed ranging from 4000 to $8000 \mathrm{rpm}$, and feed rate ranging from 8 to $10 \mathrm{~mm} / \mathrm{min}$ for all sizes of cutting tools.

ii. The dimple surface area roughness, $S_{a}$ value gained from the experimental work ranges from 5.0 to $8.0 \mu \mathrm{m}$.

iii. The dimple surface area roughness, $S_{a}$ is not affected by the toolpath movement or dimple pattern

Based on the drawn conclusion, the future work should work out on several areas, mainly on wider machining parameters range, applying the incline milling method as well as moving on into micro tool sizes. One last critical point on micro-machining, a serious measure should be taken in terms of the tolerance and accuracy during machining, especially during the tool and workpiece/specimen set up to ensure the reliability and repeatability of the gathered data. 


\section{ACKNOWLEDGEMENT}

This research paper is the author's initial work for doctoral research and funded by Universiti Malaysia Pahang (UMP) Post Graduate Research Scheme (PGRS) grant PGRS200324.

\section{REFERENCES}

[1] M. A. Câmara et al., "State of the art on micromilling of materials, a review," J. Mater. Sci. Technol., vol. 28, no. 8, pp. 673685, 2012, doi: 10.1016/S1005-0302(12)60115-7.

[2] T. Masuzawa, "State of the art of micromachining," CIRP Ann. - Manuf. Technol., vol. 49, no. 2, pp. 473-488, 2000, doi: 10.1016/S0007-8506(07)63451-9.

[3] S. Filiz et al., "Micromilling of microbarbs for medical implants," Int. J. Mach. Tools Manuf., vol. 48, no. 3-4, pp. 459-472, 2008, doi: 10.1016/j.ijmachtools.2007.08.020.

[4] L. Chen et al., "Effects of micro-milled malposed dimple structures on tribological behavior of Al-Si alloy under droplet lubricant condition," Int. J. Adv. Manuf. Technol., vol. 98, no. 1-4, pp. 143-150, 2018, doi: 10.1007/s00170-017-0603-8.

[5] X. Chen et al., "Friction reduction of chrome-coated surface with micro-dimple arrays generated by electrochemical micromachining," J. Mater. Eng. Perform., vol. 26, no. 2, pp. 667-675, 2017, doi: 10.1007/s11665-017-2501-5.

[6] X. Chen, N. Qu, and H. Li, "Improvement of dimensional uniformity on micro-dimple arrays generated by electrochemical micro-machining with an auxiliary electrode," Int. J. Adv. Manuf. Technol., vol. 80, no. 9-12, pp. 1577-1585, 2015, doi: 10.1007/s00170-015-7147-6.

[7] E. Graham, C. I. Park, and S. S. Park, "Fabrication of micro-dimpled surfaces through micro ball end milling," Int. J. Precis. Eng. Manuf., vol. 14, no. 9, pp. 1637-1646, 2013, doi: 10.1007/s12541-013-0221-9.

[8] J. C. Aurich et al., "Surface quality in micro milling: Influences of spindle and cutting parameters," CIRP Ann., vol. 66, no. 1, pp. 101-104, 2017, doi: https://doi.org/10.1016/j.cirp.2017.04.029.

[9] G. Kiswanto, D. L. Zariatin, and T. J. Ko, "The effect of spindle speed, feed-rate and machining time to the surface roughness and burr formation of aluminum alloy 1100 in micro-milling operation," J. Manuf. Process., vol. 16, no. 4, pp. 435-450, 2014, doi: 10.1016/j.jmapro.2014.05.003.

[10] S. Dehen et al., "Milling parameter and tool wear dependent surface quality in micro-milling of brass," Procedia CIRP, vol. 87, pp. 95-100, 2020, doi: 10.1016/j.procir.2020.02.024.

[11] K. Hamaguchi et al., "Effect of tool tilting angle on tool wear and surface roughness in micro ball end milling," Advanced Materials Research, vol. 325. pp. 606-611, 2011, doi: 10.4028/www.scientific.net/AMR.325.606.

[12] M. Boujelbene et al., "Tool wear analysis of ball nose end mill in the finish machining of free form surfaces," Mater. Today Proc., vol. 26, pp. 1289-1292, 2020, doi: https://doi.org/10.1016/j.matpr.2020.02.257.

[13] L. Zhou et al., "Semi-analytic modelling of cutting forces in micro ball-end milling of NAK80 steel with wear-varying cutting edge and associated nonlinear process characteristics," Int. J. Mech. Sci., vol. 169, no. November 2019, p. 105343, 2020, doi: 10.1016/j.ijmecsci.2019.105343.

[14] J. H. Ji, C. W. Guan, and Y. H. Fu, "Effect of micro-dimples on hydrodynamic lubrication of textured sinusoidal roughness surfaces," Chinese J. Mech. Eng. (English Ed., vol. 31, no. 4, p. I.d no 67, 2018, doi: 10.1186/s10033-018-0272-z.

[15] Olympus, "Concepts in Confocal Microscopy," Official Website, 2020. [Online] Available: https://www.olympuslifescience.com/ [Accessed: Jul. 27, 2020].

[16] G. Beruvides et al., "Surface roughness modeling and optimisation of tungsten-copper alloys in micro-milling processes," Meas. J. Int. Meas. Confed., vol. 86, pp. 246-252, 2016, doi: 10.1016/j.measurement.2016.03.002.

[17] T. Pratap and K. Patra, "Micro ball-end milling - an emerging manufacturing technology for micro-feature patterns," Int. J. Adv. Manuf. Technol., vol. 94, no. 5-8, pp. 2821-2845, 2018, doi: 10.1007/s00170-017-1064-9.

[18] S. Wojciechowski et al., "Investigation on the edge forces in ball end milling of inclined surfaces," Int. J. Mech. Sci., vol. 119, pp. 360-369, 2016, doi: https://doi.org/10.1016/j.ijmecsci.2016.10.034.

[19] J. Resendiz et al., "Directional friction surfaces through asymmetrically shaped dimpled surfaces patterned using inclined flat end milling," Tribol. Int., vol. 91, pp. 67-73, 2015, doi: https://doi.org/10.1016/j.triboint.2015.06.025. 